\title{
The Case for a Multi-Methodological, Cross-Disciplinary Approach to the Analysis of ICT Investment and Projects in the Developing World
}

\author{
Laura Hosman \\ Department of Environmental Science, Policy \& Management, \\ University of California, 2124 McKinley Ave \#6, Berkeley, California 94703, USA. \\ E-mail: hosman@berkeley.edu \\ Elizabeth Fife \\ Institute for Communication Technology Management, \\ Marshall School of Business, University of Southern California, Citigroup Center, \\ 444 S. Flower Street, Suite 1001-D, Los Angeles, California 90089-8204, USA. \\ E-mail: fife@marshall.usc.edu
}

\section{Laura Elizabeth Armey}

Political Economy \& Public Policy, Department of Economics, University of

Southern California, Los Angeles, California 90089, USA.

E-mail:armey@usc.edu

\begin{abstract}
This article makes the case for greater collaboration and communication between scholars and practitioners of information communications technology (ICT) for development projects and for the use of multi-methodological, cross-disciplinary approaches to understand what will make for more successful endeavors in this important arena, the necessity of which is reflected in the widespread use of public-private partnerships. To this end, we utilize both macro- and micro-level analyses to examine ICT investment in the developing world. The first research question-can ICT investment be shown to contribute to economic growth?-is addressed through econometric analysis. Though our model finds evidence to the affirmative, macro-level models often do not account for how ICT funds are employed, differentiate growth effects, or discern the characteristics of specific initiatives that make them more or less likely to succeed. This is where the case-study level of analysis becomes essential. This approach is used to address our second research question: whether successful strategies found among case studies can better inform policy prescription. To this end, we present a case study of a project based in rural Vietnam, followed by a summary of findings that unifies the lessons learned. In this way we intend to shed light on policy prescription, improve the outcomes of ICT initiatives, and present a first step in the mixed-methodological, cross-disciplinary direction. $(0) 2008$ Wiley Periodicals, Inc.
\end{abstract}

Keywords: information communications technology (ict); development, economic growth; case study; econometric analysis

Sajda Qureshi was the accepting Editor for this article. 


\section{INTRODUCTION}

The level of interest and investment in information and communication technology (ICT) for the developing world has skyrocketed in recent years. This trend reflects the high and ever-increasing expectations placed on ICT in terms of its ability to enable quality of life improvement, empowerment, and economic development for the communities into which it is introduced. It is a logical expectation given that over the past two centuries, economic growth has been driven by technological change-through both invention and adoption (Easterlin, 1996; Sachs, 2005a). Economic growth has historically been seen as going hand-in-hand with quality of life improvements. Yet, it is essential to remember that the promotion of technology adoption is not an end in itself: The ultimate goals of ICT-based projects in the developing world must be the alleviation of poverty and the empowering of human beings to lead fuller lives. The challenge for those who study (and those who participate in) ICT-for-development endeavors is thus to understand how best to employ relevant technologies in pursuit of these larger goals.

McNamara (2003, p. 3) reports that the international community has not done a good job of monitoring and evaluating ICT-for-development efforts. We would like to address what we consider to be the major reasons that this is the case.

First, the concepts of human empowerment and poverty alleviation are extremely general notions that defy simple categorization or measurement. This fact underscores the importance of communication and collaboration-across methodologies, disciplines, and industries-to increase the collective understanding necessary to successfully address the topic. This article answers a call for additional research in this area to include contributions to (and we would add from) multiple disciplines (Walsham \& Sahay, 2005). A second reason may be that academics most often study phenomena that have already taken place; given the groundswell of recent activity in the ICT-for-development area-with no proven roadmap for success-the scholarly community is racing to catch up. Third, there has been a movement to ensure that monitoring and evaluation efforts are mandatory, budgeted components of projects, rather than afterthoughts or the first portion to be cut once limited funding runs out. This is a positive development, though such efforts must continue and be combined with the forming of an overview of what may work in future endeavors. It is also an area that will benefit from collaboration. To give an example, both technological efficiency and quality of life are equally worthy factor components for the evaluation of outcomes, yet such measurement will be prioritized and undertaken differently for an engineer than for an anthropologist.

Since multiple approaches provide a fuller understanding, this article thus represents a first step in the multi-disciplinary, collaborative direction. It provides both a macrolevel econometric analysis and a micro-level case study. Combining and contrasting the quantitative with the qualitative allows us to address the strengths and shortcomings of each approach and illustrate how each methodology is strengthened by the other's contribution. It is also informed by a variety of academic disciplines, including economics, political science, and information, technology, and development studies. Further, the case study information was obtained from first-person interviews with the project's coordinator-an important aspect of collaborative (or cross-industry) research, while the case itself is an example of a public-private partnership and involved the cooperation of multiple stakeholders.

The quantitative section of this article specifically addresses the assertion that "the role of ICT in enhancing income and human development... is yet to be empirically tested using data from developing countries" (Baliamoune-Lutz, 2003, p. 152). While a limited number 
of authors have, in fact, addressed ICT-related issues using developing country data, most of them have arrived at negative or, at best, mixed results regarding economic growth or returns to capital for developing countries (Dewan \& Kraemer, 2000; Pohjola, 2001; Seo \& Lee, 2006). Making use of more recent data, our analysis finds positive economic returns to ICT investment for developing world countries, which is in line with similar findings regarding ICT's returns to productivity by Papaioannou and Dimelis (2007).

Successful projects often require that the involved partners be diverse in nature- as in the Quang Ngai case presented in this article. Reflecting this reality, academics need to collaborate across disciplines and make use of understandings brought forth from multiple fields of study - social science, business, engineering, development studies, and information technology. In addition, previous studies have argued that partnerships are necessary for projects to be both scalable and sustainable, and that within the context of such projects, the technology recipients must be involved at every stage (see, e.g., Hosman \& Fife, 2008). This article's focus on both the sustainability and the scalability of projects further addresses what Walsham and Sahay (2005) have identified as "important but neglected topics" (p. 17).

ICT is an enabling tool: It is the practical application of knowledge in the areas of information and communications. Although the introduction of new technologies is often a disruptive process - and such disruption may be unavoidable when the aim is to change a status quo as ingrained as endemic poverty - we must endeavor to understand how best to deploy them and which are most appropriate to the situation. Accordingly, there is room-in fact, there is a need - for scholars and practitioners from all relevant areas and disciplines to contribute their insights and experiences. The collaboration of many different groups is necessary for a broad understanding. Light must be shed by development scholars on holistic and sustainable approaches to poverty alleviation, political scientists on the governmental and regulatory role, economists on what economic or productivity contribution such projects can make, environmental sciences on the concepts of sustainability and partnering, designers and engineers on locally appropriate technology, anthropologists on how technology will affect people's lives, and business scholars and practitioners on how to make ventures profitable and inform our concepts of stakeholder involvement. Businesses and governments are necessary to fund the projects, provide technical expertise, governance structures, and regulation. And, of course, users of technology must complete the feedback loop to inform how technology would be useful to them. This is not an attempt to formulate a complete list. It serves to illustrate, rather, that involvement from all of these groups is vital to ensure that projects that affect these many areas will be successful and that misunderstandings will not persist. Attempting to make proclamations about ICT for development informed by assumptions from a single discipline or from a single example will not lead to fruitful insights.

Using our findings and drawing upon those of others, we will make recommendations about the kind of analysis needed to help policy makers maximize scarce resources and harness ICT investments to provide economic benefit and quality of life improvement in the developing world. Armed with a more rigorous understanding of factors affecting the use of technology in developing economies, governments, international organizations and industry can create programs better able to address problems.

The article proceeds as follows. After a brief literature review and discussion of methodology, an econometric regression is presented to measure economic growth due to ICT investment, and the results are discussed. A quantitative benefit from ICT investment in a broad sense is shown; yet, a look at the details of specific cases shows more clearly how projects that make use of ICT can provide dramatic changes in quality of life and 
opportunity. Following the case study of a public-private partnership in rural Vietnam, a discussion of best practices and commonalities is presented, along with a discussion of what each methodology can contribute. We conclude with an overview of our findings and a call for future research.

\section{THE PROMISE OF ICT FOR DEVELOPMENT}

Some critics question the value of ICT in the developing world, arguing that ICTs are a luxury that the poor cannot afford. We believe this point of view represents a misunderstanding of the situation: ICT is a means to help alleviate poverty, not an end. In truth, no person, rich or poor, needs ICT to survive. The relevant task, instead, is to determine where needs exist and, where relevant, to strive to meet them with the appropriate technology. This article seeks to establish a comprehension of ICT as an enabling tool capable of improving the quality of people's lives, alleviating poverty, and promoting economic growth. A better understanding of the root causes of both poverty and economic growth, as well as what constitutes an improvement in people's quality of life, is extremely important. Armed with such a comprehension, it is possible to proceed with a better understanding of how ICT can contribute to the human development process. The end goal must be poverty reduction and quality of life improvements, not simply an increase in the number of laptops, computers, and mobile phones around the world.

As stated above, we believe that scholars and practitioners from all relevant areas have much to teach and learn from one another. It is held as a general fact across the literature's disciplinary boundaries that economic growth is considered a positive indicator for development. As such, we include an analysis that focuses on economic growth. However, we recognize that economic growth is but one indicator.

Another widely-held belief is that governments and other relevant public entities play essential roles in the poverty-alleviation and human development efforts for a variety of reasons (see, e.g., Labelle, 2005; Mutula \& Van Brakel, 2007; Sachs, 2005b). First, as has been indicated, ICT is seen as an enabling tool for meeting primary development challenges in such areas as education, health, and infrastructure, the promoting of smalland medium-sized enterprises (SMEs), and the protection of the environment. Each of these areas is considered a public good or service in the wealthy world, and governments actively provide, protect, or promote their adoption or uptake (Mutula \& Van Brakel, 2007). This is because markets will not rise to address needs in the absence of the profit motive; hence the concept of a public good or service. Governments must step in and provide them.

In developing nations, if the home government is not able (in the case of poor, weak, or highly indebted states) or not willing (in the case of despotically run states) to provide such goods and services, other public bodies, such as state-sponsored aid agencies from wealthy countries, are increasingly taking the initiative. These external agencies choose to fill the role in recognition that economic and human development are not zero-sum propositions-meaning that everyone can benefit-and that geographic distance from the poor is no longer a relevant constraint or factor. In fact, extreme poverty tends to lead to destabilized environments: They serve as incubators for wars, disease, and terrorism, the repercussions of which are felt on a global scale (Sachs, 2005b). It is both more humane and less expensive to invest in human development.

Another major point of agreement among development scholars is that the United Nations' Millennium Development Goals (MDGs, which were adopted unanimously by all 
UN member states in 2000) can serve as important benchmarks for measuring development progress. In addition, they form a framework for the enumeration and addressing of the areas of socioeconomic, political, and cultural development essential to the reduction of human suffering from extreme poverty and the raising of the level of empowerment and participation of the world's poor. Still, ICT is recognized as such an important component of development today that it merits special mention in Millennium Development Goal Number 8, which calls for making available the benefits of new technologies-especially information and communications technologies—and specifically in cooperation with the private sector.

Consequently, public-private partnerships (PPPs) - agreements between private-sector, for-profit businesses and developing country public sector actors-have come to be held in extremely high estimation by those seeking ICT solutions to development challenges. These partnerships enjoy broad support and are actively promoted by governments, private firms, non-governmental organizations (NGOs), and international organizations alike.

In 2002, at the United Nations World Summit on Sustainable Development, a number of guiding principles for sustainable development partnerships were put forth (Kara \& Quarless, 2002). The main concept underlying any partnership is that it is created to achieve goals that could not be realized by a single party acting alone. The following principles were also enumerated:

- Partnerships are based on mutual respect and the shared responsibility of those involved.

- Each partner's role, as well as its objectives, intended outcomes, and benefits, should be clearly defined and transparently reported on a regular basis.

- Partnerships should integrate the economic, social, and environmental dimensions of sustainable development into their design and implementation and should be consistent with poverty reduction strategies where their implementation takes place.

- Partnerships should have a multi-stakeholder approach and involve a range of significant actors in a given area of work. They can be arranged among any combination of partners, including governments, regional groups, local authorities, NGOs, and those from the private sector. All partners should be involved from an early stage, so that the approach is genuinely participatory. Yet, as partnerships evolve, there should be an opportunity for additional partners to join on an equal basis.

- Partnerships should add value in terms of human development goals.

These principles can serve as valuable guidelines for future partnerships undertaken in the developing world. Accordingly, they, as well as the Millennium Development Goals, will serve to inform our findings and discussion of best practices following the Quang Ngai case study below.

In addition to the importance of forming partnerships in order to create sustainable ICT-for-development projects, itself a paradigm-shifting notion, we further assert the importance of focusing on the long-term sustainability of such projects. To do so will require actively involving the local technology recipients and considering them stakeholders throughout the duration of the project to create a culture of use for the technology. This involves understanding their wants, needs, and the specific situations facing the local communities; no ICT-for-development project can be considered a one-size-fits-all scenario. 


\section{METHODOLOGY}

This article provides both quantitative and qualitative methodologies in the attempt to promote a multi-methodological, multidisciplinary approach to ICT-for-development and to demonstrate that each technique has valuable information to provide the other. We present a macroeconomic model that focuses on economic growth. Though it finds results in the affirmative, economic growth is but one area of human development and, as with all macro models, it fails to inform on a policy-relevant micro level. This is where case-level analysis becomes essential. Our case study illustrates important concepts that the macro level cannot address: relevant issues such as the involvement of local stakeholders, the importance of partnering in such projects, of determining real needs so that ICT can help address them, and of intangible, quality of life issues such as the importance of being able to place an inexpensive telephone call to family or neighbors where this capability did not exist before. Our micro-level study will in turn inform the macro-level study.

The topic of ICT for development comprises a number of academic subject and interest areas, including, but not limited to, economics, business (ethics) studies, information systems, technology studies, sociology, politics, and development. Accordingly, this overview draws from a wide range of sources.

\subsection{Literature Review}

In the literature of theoretical economics, endogenous growth theory (or new-growth theory) stipulates that it is technology and human capital, when endogenously present, that contribute to continuous economic growth and play an essential role in a country's development (Easterly, King, Levine, \& Rebelo, 1994; Barro, 1997). Logically, workers who are better educated, better fed, healthier, and technologically capable can produce more than those who are illiterate, hungry, unhealthy, and unskilled.

Robert Barro's (1991) statistical analysis of differences in growth rates across a large number of countries reveals that a high initial level of human capital has a significant positive effect on growth. This growth, in turn, further raises the level of human capital, etc., thus forming a virtuous circle. We can predict that ICT penetration-the ability to use technology to increase efficacy and efficiency-would have the same reinforcing effect.

A number of academics from the field of economics have researched the role that ICT can play to fight poverty and catalyze socioeconomic development and growth. There have been a number of macro-level studies demonstrating the positive impact of ICT on economic growth and development (see, e.g., Roller \& Waverman, 2001; Cronin, Colleran, Parker, \& Dollery, 1993; Norton, 1992). These studies have utilized data from the developed world. Only a limited number of studies have addressed the same issues as they apply to developing world countries and, to date, most of these present mixed results at best. Dewan and Kraemer's (2000) findings indicate positive and statistically significant returns to ICT capital investments for developed countries but non-significant results for developing countries. The authors conclude that developing countries lack a substantive base of capital stock and infrastructure necessary for ICT investment to bring about a positive result. In a similar vein, Pohjola's (2001) cross-sectional study across 39 countries from 19801995 reveals that ICT investment has no significant impact on economic growth when all the countries are included; when he removes the developing countries from the sample however, he finds a strong influence on growth from ICT investment in the developed countries. Specifically addressing the digital divide and growth gap between developed and 
developing countries, Seo and Lee (2006) also present mixed findings. On the one hand, global digitalization has a negative impact as it widens the existing digital divide, but on the other, there is room for positive impacts through knowledge spillovers that can promote growth in the developing world.

Papaioannou and Dimelis (2007) make an important contribution with their finding that ICT exhibits a positive and significant impact on productivity around the globe. Theirs is the first study to give evidence that ICT's positive returns to productivity, long a reality for the developed world, have now begun to evidence themselves in the developing world as well. Our findings below offer a contribution along the same lines: We find positive gross domestic product (GDP) per capita returns to ICT investment across 42 developing world countries during 2000-2006. Because our findings are more robust than when we ran the same regression earlier using data from 2000-2004, we agree with Papaioannou and Dimelis' (2007) assertion that "developing countries have started to benefit from ICT" (p. 180).

Waverman, Meschi, and Fuss (2005) have found that mobile phones are having a positive and significant effect on economic growth in developing countries. In fact, they find that because mobile phones provide the primary method of communications in developing countries with no or few fixed lines, the growth impact for developing countries may be twice as great as for developed countries in which attributable growth would be split between fixed-line and mobile-phone use. Waverman et al. acknowledge the paucity of macroeconomic research that focuses on developing countries and claim that their article attempts to fill that void. We hope to contribute, in the same vein, with our quantitative analysis.

Other research has considered the social impact of telecommunications technology in the developing world. De Silva and Zainudeen $(2007$, p. 2$)$ rightly point out that such "social" use of ICT is not to be considered frivolous-the ability of family members to stay in touch with one another contributes to a better quality of life.

In a separate interview, Waverman also asserts that detailed analyses are important for increasing our understanding of cause and effect (Economist, 2007). This leads us to the second part of our article as research at both the theoretical and the micro level is still notably lacking in this area (London \& Hart, 2004; De Silva \& Zainudeen, 2007). This article thus contributes to the case-study/empirical evidence body of literature, presenting an illustrative ICT-for-development project taking place in rural Vietnam that features a multi-stakeholder public-private partnership. Quality of life, infrastructural needs, and economic growth were all motivating factors in this case, which is discussed below. We do, however, recognize the potential pitfalls of extrapolating generalizations from a single case study.

To provide an example, Jensen (2007) makes an extremely important contribution to the micro-level evidence of ICT's ability to increase the availability of information, in turn, enhancing market performance and improving economic outcomes for both producers and consumers. The case he uses gives evidence from Indian coastal villages in the state of Kerala where fishermen and buyers began using mobile phones to exchange price information in advance of fish being brought to market. Because the change took place over time, Jensen was able to demonstrate how the increase in information led to a more efficient market in that fishermen eventually received a higher price for their catch and consumers ultimately ended up paying less. This finding, that information provided through ICT-enabled capabilities leads to more efficient markets, is an important one for developing countries looking to improve the functioning of their markets. Yet Jensen then extrapolates that "because mobile phone service in Kerala is a private sector initiative... the private sector may be better suited to identifying such opportunities" (pp. 919-920) and that the 
spillover benefits evidenced from this private-sector led service were sufficient to alleviate concerns in India over the perceived internal digital divide (p. 920).

Auspiciously, in this particular case, there were positive spillover effects from which even the poor were able to benefit. Unfortunately, in general, spillover benefits are not sufficient to address the digital divide or ameliorate inequalities. Spillover does not empower or enable, nor does it bring about equality of opportunity. Also, while the private sector is indeed better suited to identifying potentially profitable opportunities, not every instance where ICT can contribute to human development will be profitable. Outside of Kerala, there are numerous parts of India (particularly rural areas) that still lack (affordable) ICT capabilities because telephone service providers have not deemed bringing service to them to be a profitable endeavor. Fortunately, the Indian government has recognized this and has been a leader among developing world states in its initiatives to provide ICT-enabled services to all citizens of the nation-not just to those from whom a private company can make a profit.

Jensen also points out anecdotal evidence revealing that government or NGO (public-led) projects often do not meet with success (2007, p. 919). However, other scholars point out failures when private companies pursue similar ventures in the developing world (London \& Hart, 2004). This is not sufficient reason to stop trying. It is instead a strong justification to try something different: In this case, it helps to explain why public-private partnerships are more frequently being employed in an attempt to utilize the expertise, capabilities, resources, and experience that are the strengths of each actor to address this development challenge.

Although some high-priced projects have failed, there are also numerous cases-small and large - in which benefits have been immediate and dramatic, even in conditions of extreme poverty and illiteracy. Unfortunately, both successful and unsuccessful cases remain underreported in the scholarly literature. Uneven reporting and the difficulty inherent in ascertaining and tracking results indicate the need for solid methodological approaches to the study of ICT as a tool for development. Based on their survey of scholarly contributions since 2000 in the field of information systems in developing countries, Walsham and Sahay (2006) report that progress is being made in this area; most authors utilizing case study methodology are analyzing the interaction of actors at multiple levels, as well as how these various actors implement and use IT (p. 14). Actor-Network Theory (ANT) is a methodological framework adopted by some scholars for revealing and examining the (often hidden) power relationships between the actors (Silva, 2007). Others draw from institutional theory to study processes such as decentralization within the context of the case-study methodology (Kimaro \& Sahay, 2007).

Still, Walsham and Sahay find that in-depth case studies with an interpretivist approach - the method used in this article — can be "quite solid in methodological terms" (2006, p. 14). We therefore propose this approach to our case study reporting, believing that our more innovative contribution lies in the combination of methodologies employed to inform a broader conception of best practices.

\section{MACRO-LEVEL ANALYSIS OF ICT INVESTMENT AND GROWTH}

Although the potential of information and communications technologies to influence economic growth is widely acknowledged, econometric analysis has not provided a clear demonstration for developing countries, as noted above. As a first step in our macro-level 


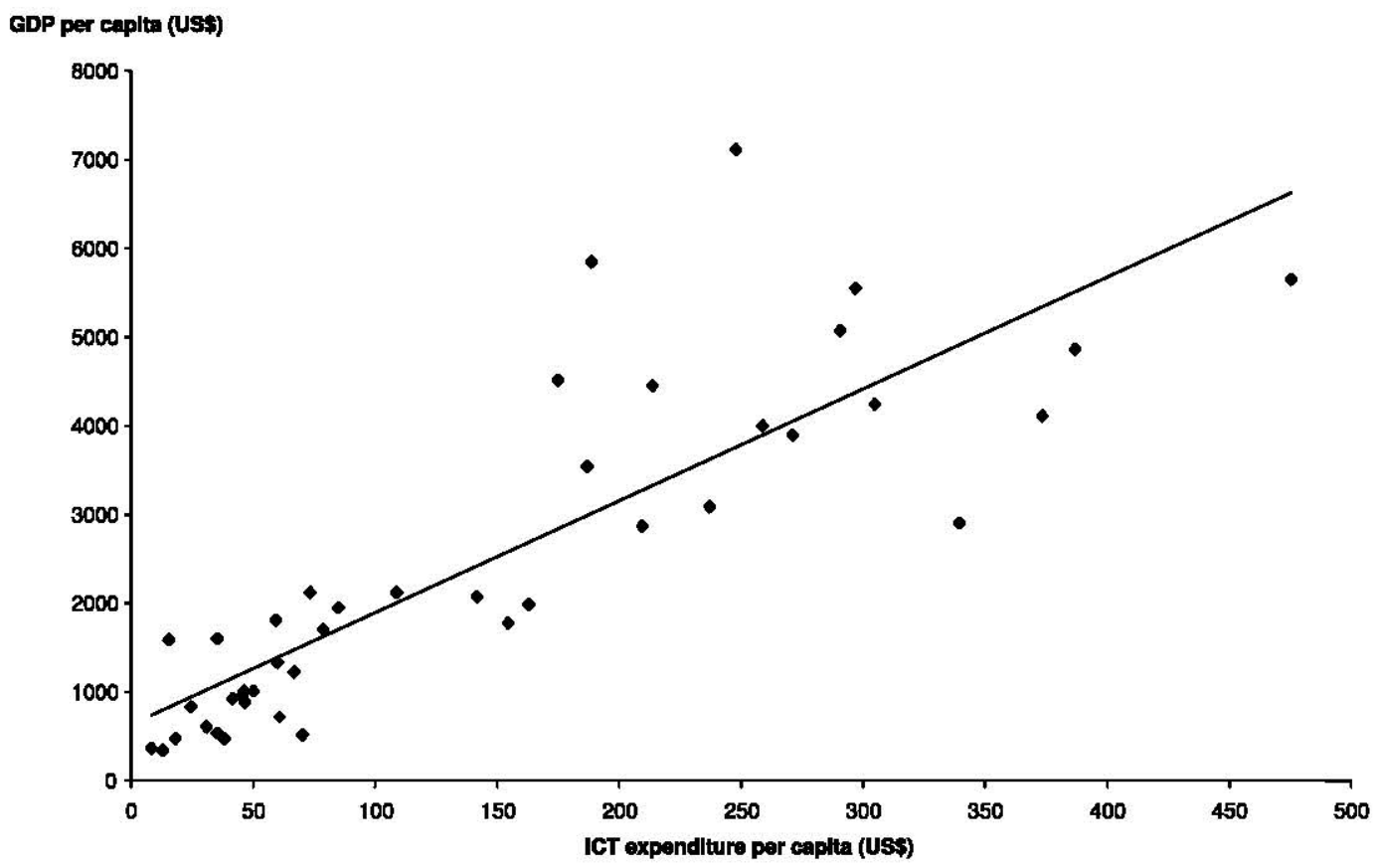

Source : World Bank, World Development Indicators, 2007

Figure 1 Correlation between GDP per capita and ICT expenditure per capita in developing countries, 2000-2006.

analysis, a simple regression was run using the averaged standard data of ICT expenditures from 2000 to 2006 (World Development Indicators; World Bank, 2004, 2007). Figure 1 is the result using GDP per capita on ICT expenditure.

This graph shows a positive correlation between per capita ICT expenditure and per capita GDP. These results were used to develop an econometric model for analysis adapted from Levine, Loayza, and Beck (2000) generalized method-of-movements (GMM) panel model.

We have adapted the GMM estimator model to test for a positive association between ICT investment and economic growth (Levine et al., 2000). However, assessment of an independent relationship between ICT investment and economic growth is limited by several factors, among them a lack of differentiated data on IT investment and problems inherent in isolating the effects of ICT investment from other influences. Numerous factors affect economic growth; controlling for these factors while determining how information technology fits in with them is but one of the challenges of measuring ICT's role in economic growth. Analysis that shows a correlation must be carefully examined in the context of the limited data that currently exists.

We have tested our model using World Development Index (WDI) panel data to estimate the effect of ICT investment on growth. With a pure cross-section regression, any unobserved nation-specific effect would be part of the error term, potentially leading to biased coefficient estimates. The existence of panel data enables us to control for unobserved country-specific effects and reduce the biases in estimated coefficients. Our panel estimator controls endogeneity of all explanatory variables by using internal instruments, assuming that the explanatory variables are only weakly exogenous. This means that future shocks to the growth rate do not affect the current ICT expenditure rate. 


\subsection{Regression Model}

The Generalized Method of Moments (GMM) estimators were developed for dynamic models of panel data introduced by Arellano and Bond (1991). Our panel is composed of 42 developing countries (as defined by the World Bank) during 2000-2006. Consider the following regression equation:

$$
y_{i, t}-y_{i, t-1}=(\alpha-1) y_{i, t-1}+\beta^{\prime} X_{i, t}+\eta_{i}+\varepsilon_{i, t}
$$

where $y$ is the logarithm of real per capita GDP, $X$ represents the set of explanatory variables (other than lagged per capita GDP), $\eta$ is an unobserved country-specific effect, $\varepsilon$ is the error term, and subscripts $i$ and $t$ represent the country and the time period, respectively. We can rewrite the above equation as

$$
y_{i, t}=\alpha y_{i, t-1}+\beta^{\prime} X_{i, t}+\eta_{i}+\varepsilon_{i, t}
$$

To remove country-specific effects, we take the first difference,

$$
y_{i, t}-y_{i, t-1}=\alpha\left(y_{i, t-1}-y_{i, t-1}\right)+\beta^{\prime}\left(X_{i, t}-X_{i, t-1}\right)+\left(\varepsilon_{i, t}-\varepsilon_{i, t-1}\right)
$$

The new error term is correlated with the lagged dependent variable. Hence, we cannot obtain an unbiased estimate by using the ordinary least squares (OLS) method. However, under the assumptions that the error terms are not serially correlated and that the explanatory variables are weakly exogenous, the GMM dynamic panel estimator uses the following moment conditions:

$$
\begin{aligned}
& E\left[y_{i, t-s}\left(\varepsilon_{i, t}-\varepsilon_{i, t-1}\right)\right]=0 \quad \text { for } \quad s \geq 2 ; t=3, \ldots, T, \\
& E\left[X_{i, t-s}\left(\varepsilon_{i, t}-\varepsilon_{i, t-1}\right)\right]=0 \quad \text { for } \quad s \geq 2 ; t=3, \ldots, T
\end{aligned}
$$

Hence, we can use the lagged values as instruments for the regression in differences. The consistency of the GMM estimator depends on the validity of the instrumental variables. Arellano and Bond (1991) suggested using a Sargan test of over-identifying restrictions, which tests the overall validity of the instruments by analyzing the sample analogue of the moment conditions used in the estimation process. In addition, this estimator relies on the assumption that error terms are not serially correlated. In the event, we utilized the Sargan test, but we could not test the lack of correlation of error terms because we do not have data covering a sufficiently long time period.

\subsection{Results}

In Table 1, each of the coefficients corresponds to the effect on the growth rate of each of the explanatory variables.

In the regression equation, the dependent variable is the first difference of log of GDP per capita, which is the linearized economic growth rate. The explanatory variables consist of the $\log$ of ICT expenditure per capita, the log of the inflation rate, the $\log$ of openness made up of the sum of exports and imports, and the log of secondary school enrollment rates. Due to the potential nonlinear relationship between economic growth and the assortment of economic indicators, we use a natural logarithm of the regressors. Our main concern is whether there is a significant exogenous effect of ICT investment on the growth rate when 
TABLE 1. Regression Results

\begin{tabular}{lc}
\hline Independent Variables & GDP Growth \\
\hline First Difference & $0.1059686^{* * *}$ \\
Openness & $(0.0224)$ \\
First Difference & $0.0899795^{* * *}$ \\
ICT per capita & $(0.0145)$ \\
First Difference & -0.1082993 \\
Schooling & $(0.1492)$ \\
First Difference & $-0.265762^{* * *}$ \\
Inflation & $(0.0365)$ \\
Lag GDP & 0.00099 \\
& $(0.0016)$ \\
\hline
\end{tabular}

Note. The numbers in parentheses indicate standard errors. ${ }^{* * *}$ indicates significance at the $1 \%$ level.

controlling other important variables, such as human capital and economic stability. We use the ICT expenditure per capita variable as the proxy for the net investment value of ICT. The secondary school enrollment rate is used to control for the level of human capital; the inflation rate and openness are used to capture macroeconomic stability. The school enrollment rate and inflation rate are included as $\log (1+$ variable $)$.

The dynamic panel estimates show the significant exogenous effect of ICT investment on economic development at the $1 \%$ test level. A $100 \%$ increase of ICT expenditure per capita produces an additional $9 \%$ increase in the growth rate. The estimated coefficient is not large, but it is statistically significant and not negative.

Most of the control variables behave as expected. The coefficient of the inflation rate is negatively significant and large compared to that of ICT expenditure. Macroeconomic instability can be interpreted as being harmful to economic growth. This result is consistent with our anticipation. Developing countries must ensure the stabilization of the national economy in order to achieve high growth. Similarly, openness of the economy as a variable is positive and significant. Secondary schooling, the control variable for human capital, is positive, as expected, but insignificant. Secondary schooling is not a perfect proxy for human capital, and the model covers only a short time period, which limits this otherwise arguably important variable. The only counterintuitive finding is the negative coefficient on lagged GDP, but the magnitude of the coefficient is very small.

To test the accuracy of the model, we consider the Sargan test. According to the Sargan test result the instruments used herein are not correlated with the residual. (Again, we could not test serial correlation of error terms since we do not have data with sufficient time span.)

After controlling for country-specific fixed effects, endogeneity, and potential problems associated with lagged dependent variables and weak instruments, our data implies a strong positive link between ICT investment and economic growth. Even taking into consideration the potential problems of the weakly exogenous assumption and nonlinearity, this finding is meaningful in terms of developmental policy implications. At a minimum, the results suggest the need for more advanced research.

At this time, conventional econometric approaches remain limited as the data necessary to measure this relationship accurately enough in developing countries are not yet extant. If we run a linear regression using the modified GMM model we have developed with the best data available, it is possible to see a relationship, but we still cannot fully explain the reasons for this. We do not have a breakdown of ICT investment to indicate how funds were spent, that is, in which sectors and for what purposes. Even so, when we analyze the 
variables using logarithmic calculations, we see a significant relationship between growth and ICT investment.

That we see significance when using a log transformation for some of the variables is an indication of, and support for, the hypothesis that ICT can support growth in developing countries. It is possible that some of the variables we have isolated have exponential rather than linear growth. An additional complication is the fact that ICT spending is often embedded within other development-oriented projects in various sectors such as health and education, which means that it is difficult to correctly measure actual ICT spending (McNamara, 2003). Although this fact makes macro-level estimates more difficult to obtain, it should be regarded in a positive light because, as we have argued, ICT should correctly be regarded as an enabling tool in all sectors. To separate out ICT-only investment would in fact point to this technology's non-integration in both concept and reality.

Although we cannot say under what conditions this is the case or how best to implement ICTs to maximize growth, micro-level analyses can be used to fill in some of the gaps. In fact, these may constitute the most appropriate approach for examining the effects of ICT investment in developing economies. The fundamental question-does ICT investment exert a positive influence on economic growth?-has clear implications for government planners, yet we cannot use macro-level analysis to address more specific policy questions. Thus, we supplement quantitative analysis with case-based data that reveals key requirements for ICT projects to succeed.

\section{SUPPLEMENTING QUANTITATIVE ANALYSIS WITH QUALITATIVE: CASE STUDY OF QUANG NGAI TELECOM DEPLOYMENT}

The case highlighted in this section describes a project that is a public-private partnership initiative to bring affordable telecommunications capability to the Quang Ngai province of rural Central Vietnam. It is a proof-of-concept pilot project designed to improve local opportunities for both economic and social capacity-building. However, the story actually begins earlier.

\subsection{Background}

One of the actors in this project is the U.S. Agency for International Development (USAID), which has recognized the important role that ICTs can play in the human development process. As a result, USAID has begun a campaign promoting the opening up of state-monopoly telecom sectors to increased competition throughout the developing world countries wherein they have development programs. This is one aspect of USAID's Last Mile Initiative (LMI), a global program, launched in 2003, to bring modern telecommunications infrastructure to farmers and small businesses in traditionally underserved rural areas. To this end, it has been funding a number of country-specific ICT projects that make use of new, creative, and promising approaches for expanding telecommunications access.

One of the unique aspects of USAID's mission for such projects is that LMI programs are designed to be self-sustainable and subsidization-free once they are up and running. USAID promotes this sustainability; it generally has an end-date for its participation, after which it departs, its funding stops, and the remaining partners fully take over the project.

The Vietnamese government, for its part, is taking a pro-active role in promoting ICT for development. The government has liberalized its telecom sector, implemented a universal (telephony) service program, and established funds as well as an entity within the Ministry 
of Post and Telecommunications to carry out this endeavor (the Vietnamese Telecommunications Fund, or VTF).

There were two previous pilot projects from which the Quang Ngai deployment-the focus of this case study - was able to learn. These two projects brought ICT capabilities to the rural agricultural villages of Lao Cai and Sapa in the mountainous North of Vietnam. The villages in these first pilots were chosen specifically because of the economic benefits the residents could realize if they were able to communicate inexpensively with their Chinese neighbors, just across the border, to promote trade. The project's emphasis was on enabling voice communications as this was the capability the local residents expressed the most desire to have. Local people were consulted both prior to and during the project's implementation. In Vietnam, strong provincial governments operate within the state's regions and the head of the Lao Cai People's Committee was a local champion of the project; this lent the project considerable local credibility and support.

The projects made use of some notable technological innovations to lower costs and increase effectiveness for the ICT recipients, including Voice over Internet Protocol (VoIP), Satellite and WiMAX technology, and lower energy requirements to power the hardware (which opens up the eventual possibility for solar energy to provide sufficient power).

VoIP currently represents the least expensive method of voice communication in existence. The wireless technology enabled the network to be available across a larger geographical area than was previously possible and avoided the prohibitively expensive costs of laying telephone lines. Lower energy cost requirements also lower long-term operational costs. These technological innovations effectively minimized both short- and long-term costs by enabling both voice communications - the locally desired capability-and Internet service, for which demand may increase over time, with a single technology deployment. They also demonstrate a way to avoid what has been identified as a constraint elsewhere in the developing world: a reliable source of electricity to implement ICT-for-development projects. ${ }^{1}$

One of the goals for all of these deployments is to design a program that would be self-sustainable in the longer term so that further subsidization would not be required once the programs were up and running. In other words, if, after the initial investment and start-up costs are incurred, such projects can become profitably run by a local municipality or entrepreneur, and ongoing governmental subsidies would no longer be necessary. This concept of long-term sustainability is central to the realization of this and similar projects in the future: It ensures that the projects are not seen as handouts by the recipients but rather infrastructure-building programs that enable citizens to communicate more efficiently and increase the number of economic, educational, informational, and health-related opportunities available to them.

\subsection{Public Private Partnership in Quang Ngai}

Partners involved in the Quang Ngai project are as follows: the village residents, a Vietnamese telecommunications service provider, World Resources International (WRI, the project coordinator ${ }^{2}$ ), USAID, Intel, the provincial government, and RUDEP (an initiative jointly funded by AusAID and the Australian government). This represents a continuation of-and expansion upon-the partners that participated in the pilot projects in Lao Cai.

\footnotetext{
${ }^{1}$ For a more thorough description of these two pilot projects, please see Fife and Hosman, 2007.

${ }^{2}$ The information for this case study was provided by the project coordinator, Allen Hammond, from WRI.
} 
It also demonstrates both the importance of involving numerous and diverse partners to realize such a project and the possibility of doing so successfully. The partners in this project range from local to international actors and came from all sectors relevant to the successful rollout of the project, which is built on the experience, expertise, strengths, and capabilities unique to each contributor.

\subsection{Calibration of Technology to Needs}

The larger-scale Quang Ngai project builds on the successes of the pilot projects, while adopting improvements, the first of which is the ability to utilize the development efforts of RUDEP that are already underway. Quang Ngai had already been identified by AusAID and the Ministry of Planning and Investment as a suitable location for a rural development and poverty reduction program due to the Province's high percentage of rural poor, slow economic growth, and limited previous Official Development Assistance. RUDEP's goal is to contribute to rural development, governance, and poverty reduction by empowering poor households through activity groups formed to design and implement activities throughout the communes. The aim is for rural households to increase their self reliance and the capacity and confidence to access services and resources needed to improve their livelihoods through participation in these activity groups. The households thus become active in the development of their communes and able to influence the decision-making process for projects (Quang Ngai Rural Development Program, 2007).

Workers from RUDEP had already been residing in Quang Ngai villages for over a year, and they had begun interviewing and educating the residents (in the local languages) about the project's features and potential benefits and asking them what they desired from the technology before the project was deployed. In addition, RUDEP's monitoring and evaluation activities made possible an assessment of the coincident state of telecommunications infrastructure, level of socioeconomic development/activity, and environmental conditions.

The three communes involved with the Quang Ngai deployment were selected in cooperation with the provincial government with the goal of serving the rural communities there. The communes represent diversity in terms of geography, ethnicity, and socioeconomic status; they are located in the third poorest region in the country (Hammond, 2007).

People's Committees are actively involved in each community, which, as stated above, was also the case in the Lao Cai projects. Given that the People's Committee heads became project champions in the pilot projects, a similar outcome is anticipated for the Quang Ngai project; this bodes well for the prospects of the project's acceptance throughout the province. Committee heads are not the only village leaders involved: The heads of the Women's Communities have also been consulted.

Other improvements for the Quang Ngai project involve technological developments. First, the Wi-Fi technology has been both improved and simplified. The project employs a Wi-Fi mesh technology, with two radios in a box (one of these connects to other radios while the other connects to the user), which is attached to the top of a pole. These components offer an improved design for outdoor use, and the technology employed has also been optimized for greater distance of receptivity. Additionally, both the technology and the deployment have been simplified (for the end user) so that local residents can handle both deployment and simple repairs. Thus, the expense of sending out specialized repair people to remote locations is saved. Also, the system can be monitored-and often repaired-on a remote basis, offering another opportunity for cost-savings (Hammond, 2007). 
There have also been technological advances in the VoIP system. For example, within the wireless network, there is a switch that either allows or disallows the carrying of voice. An additional switch has been installed that allows for local-only calls to be placed and kept local; they do not go through the rest of the network. This will allow the service provider to charge a flat fee for unlimited local calling (the estimated fee is 50 cents per month) and a per-minute rate for long distance calls (this is along the lines of a Skype calling plan, where calls cost a few cents per minute). The Wi-Fi network allows for full transmicity between telephones and computer-placed calls.

Other technological improvements are to be employed on the large-scale project; principal among them is the "greening" of the network's energy. Cellular towers in remote areas have traditionally been diesel powered. This project makes use of Wi-Fi towers with radio boxes that cost significantly less to build and deploy and nearly nothing to power. The key consumer access device, at this point, is the Wi-Fi-enabled phone, a basic mobile phone with a Wi-Fi chip. Building this communications infrastructure on Wi-Fi maintains the potential for future broadband Internet use for businesses that are able to pay for access and for the government to provide services through schools and clinics.

Due to the improvements in technology and the economies of scale being employed, cost savings are tremendous. The project's capital requirements (at scale) are estimated to be less than US\$3 per person, while the Internet and communications costs of utilizing the Wi-Fi network come to less than \$1 per household per year (WRI estimates). These figures exclude the costs of the phones, which make use of the network through the installed Wi-Fi chip. However, major mobile phone companies, recognizing the potential this market represents, have already begun to manufacture inexpensive mobile phones, while the Wi-Fi chips are expected to cost between $\$ 5$-to- $\$ 7$. The prospective cost savings are sufficient to allow telecom companies to offer a lower tier rural pricing system and still maintain profitability while developing a future broadband Internet customer base. Thus, there is a profit-making business model enabled here, and the potential server in this case is a local Vietnamese telecommunications service provider.

One concrete example of a quality-of-life improvement identified by the villagers themselves involves the distance education experience for local families. For many households in these villages, the schools are located miles away from their homes. As a result, during monsoon season, many parents simply do not send their children to schools as the parents worry for the safety of their children on the journey to and from the school and have had no method for communication with each other. Villagers have expressed to RUDEP workers that if they had the possibility of ascertaining their children's safety, they would be more inclined to send them to school. It is therefore anticipated that school attendance will increase as a result of ICT capabilities.

To the extent that quality-of-life improvement objectives are met, this project can serve as an exemplar to inform future ICT efforts in the developing world. Although generalizing from a single case can be problematic, it nonetheless constitutes a first step in knowledgebuilding for best practices.

\section{SUMMARY OF FINDINGS}

The implementation of the Quang Ngai project was scheduled for completion in January, 2008. It is thus too soon to comment on the long-term outcome of this case for the communities involved: whether the technology has been adopted, whether it has led to economic activity and growth, and whether it will lead to improvements in the areas of health and 
education and to other socioeconomic benefits. Even so, the project has been deemed successful on several fronts, and we can identify several practices and characteristics common to the successful implementation of ICT projects. The partnering and local involvement in this case study are in line with a number of the Guiding Principles for Partnership mentioned above and will serve to frame our discussion of successful characteristics.

The first success factor involves identifying appropriate partners for the public private partnership, and the partnerships must be based on mutual respect and shared responsibilities. All must be interested in the long-term sustainability of the project and interested in the bigger picture - the enabling of the technology recipients and improvement of the quality of their lives. Also in line with the guiding principles, all partners were involved from an early stage of the project, and this project was designed with poverty reduction strategies and long-term sustainability as core project goals. It is also essential to recognize that there are more than just two parties involved in a public-private partnership and that though these partnerships may be complicated to form and to make function, they are worth the effort-in fact, they are essential.

The second identified characteristic of successful projects is that they begin with a proofof-concept pilot project. Even though each partner's role and objectives may be clearly defined at the outset, smaller projects are more easily adapted to changing conditions, and certain problems or challenges can be identified and more easily remedied at an early stage. Efforts that prove to be in line with local realities and appropriate to local socioeconomic conditions are more likely to be adopted by local residents. There can be large returns from low-cost projects, and even successful, scalable projects often begin as pilots, the successes of which may inspire confidence in both investors and government to "think bigger."

The third characteristic is that the technology appropriate to the project is identified. Simpler is often better. In this case, some of the newest available technologies were utilized, but they were, in fact, the most appropriate as they led to the least expensive outcomes at the end of the day. The technology was deemed appropriate because it brings telephony at the lowest cost available while at the same time providing Internet connectivity. This technology was, in fact, both cutting-edge and simplified, and it also helped to address the problem of the region's varied terrain. In the end, the choice of technology must be determined by the project's characteristics - there is no one-size-fits-all technological solution that will prove to be best and most appropriate across the entire globe.

A fourth characteristic necessary for the success of this project is the nature of the state's telecom sector. In this case, it was liberalized, with the presence of real competition. Also essential to this case is the government's desire to implement universal telecommunications service.

The fifth characteristic is that local communities and citizens have been involved from the outset in this project. They know that they are stakeholders in what could otherwise seem to be top-down, paternalistic, and foreign projects. Involving communities and adding value in terms of human development goals includes both inquiring of residents what their needs and wants are and educating them as to what ICT can do for them. The enthusiasm and commitment of decision makers is a factor common to most successful cases, and the presence of a local project champion can help greatly with local acceptance. Services that are seen to be useful and demonstrate their utility quickly will be used in everyday life, which also encourages adoption. Buy-in by citizens is much more likely if services demonstrate an improvement over the status quo.

A challenge that will remain for the Quang Ngai project is the ongoing monitoring necessary to determine whether the technology will be adopted by the local residents; only 
time will tell whether the people of these cities will take advantage of the technologies beyond their use for simple communications and whether other areas, such as education and health care, in which ICT can make a positive contribution will develop as well. It also remains to be seen whether, as initially anticipated, local residents will adopt ICT for their economic benefit. A further challenge exists regarding the financial sustainability of the project: Although the government is financially committed to providing universal service, it is preferable that the local economy develops and the project becomes self-sustaining. The possibility exists for it to become so. Whether this will happen will be seen in time.

Our macro-level analysis revealed that ICT-related investment resulted in positive returns to growth, while our micro-level analysis served to illustrate more tangibly a case where policies and plans-for-action were put into place. We believe that future ICT-fordevelopment projects may benefit from the success factors that were identified as well as from future project reporting.

\section{CONCLUSION}

In this article, we have made the case for the importance of analyzing ICT-for-development projects in a multidisciplinary, multi-methodological manner, which, we have argued, will lead to a richer understanding of the topic through collaboration and give a better reflection of the reality of the multi-partnered aspect of many ICT-for-development undertakings. We represent varied disciplinary backgrounds, which the case study interview draws in practitioner insights as well. This article thus represents a first step in a multidisciplinary, collaborative research direction, which we hope will inspire like-minded contributions in the future.

Moving from the simple premise that information and communications technology offers a range of opportunities to address deep-seated poverty issues in the developing world to actual demonstrable positive effects is a useful and worthy goal. As many governments in the developing world face severe problems with providing basic education, nutrition, healthcare, and housing for their citizens, non-governmental organizations, firms, and others are looking to ICTs as an enabling tool for the promotion of growth and social development. Economic growth can lead to the feeling of empowerment experienced by people as they gain increased control over their ability to earn their income. This is why the measurement of economic growth is an important place to start and why it must be noted that our macroeconomic results indicated a positive correlation for economic growth and ICT investment in developing countries.

The quantitative section of the article utilized the most recent data available from 42 developing countries and demonstrated positive returns to economic growth from ICT investment. It contributes to recent findings that developing world countries indeed have begun to benefit from such investments, and the policy implications for developing country governments point to the importance of maintaining or increasing ICT investment.

Understanding the effect of ICT investment on growth is a vital first step toward the creation of a roadmap for emerging economies. Before we can identify how best to invest in ICTs to empower citizens and improve conditions in the developing world, however, we need a better understanding of concepts that the macro-level analysis does not provide. This is where the case-level analysis becomes essential.

The case presented in this article has relevance for policy prescription as well as for best practices for deploying ICT projects in a rural, developing-world setting. The policies put into place and carried out by the Vietnamese public sector are as follows: liberalization of the telecom sector, instituting and deploying a universal telecommunications service fund, 
and partnering with the private sector to carry out the pilot project. Best practices that are in line with the UN's Principles for Sustainable Development Partnerships were identified: identifying appropriate partners and including each of them in the long-term sustainability of the project; beginning with a proof-of-concept pilot project to identify and remedy challenges early-on; adopt technology that is appropriate to the situation and relevant to the existing societal demands of the local citizens; and finally, and perhaps most important, involving the local technology recipients as stakeholders in the project from the outset to establish feedback loops and a complementarity of bottom-up and top-down inputs.

Information gathering progress has been made on a number of successful and less successful projects, but, for the most part, these experiences are anecdotal and not systematically presented. We can identify benefits in the success stories, and yet tracking the effects of programs through the business system is an important activity too often left undone. The multitude of projects underway in the developing world provides an unprecedented opportunity to learn how social and economic change can be furthered by both traditional and more advanced technologies. The lessons we learn can perhaps be applicable to many contexts: small- and medium-sized firms, rural communities, and even local communities and firms in the developed world. Much remains to be learned about the extent of similarity and difference between the developed and less developed worlds. Greater clarity concerning the underlying drivers of adoption by individuals and organizations is an additional part of the fundamental understanding of how best to calibrate technology to meet real needs, what works to alleviate endemic poverty, and how ICT can assist in that goal.

To have a more rigorous understanding of the dynamic between growth and technology, and to understand which factors will contribute to more successful ICT-for-development endeavors, there is a fundamental need for greater collaboration and communication between academics - from a broad range of disciplines—and the practitioners who carry out the projects. This article represents a first step in that direction.

\section{APPENDIX}

\section{List of Countries}

\begin{tabular}{lll}
\hline & \multicolumn{2}{c}{ 42 Countries } \\
\hline Argentina & Hungary & Poland \\
Bangladesh & India & Romania \\
Bolivia & Indonesia & Russian Federation \\
Brazil & Iran, Islamic Rep. & Senegal \\
Bulgaria & Jamaica & Slovak Republic \\
Cameroon & Jordan & South Africa \\
Chile & Kenya & Sri Lanka \\
China & Malaysia & Thailand \\
Colombia & Mexico & Tunisia \\
Costa Rica & Morocco & Turkey \\
Czech Republic & Pakistan & Ukraine \\
Ecuador & Panama & Uruguay \\
Egypt, Arab Rep. & Peru & Venezuela, RB \\
Honduras & Philippines & Zimbabwe \\
\hline
\end{tabular}




\section{REFERENCES}

Arellano, M., \& Bond, S. (1991). Some tests of specification for panel data: Monte Carlo evidence and an application to employment equations. Review of Economic Studies, 58(2), 277-297.

Baliamoune-Lutz, M. (2003). An analysis of the determinants and effects of ICT diffusion in developing countries. Information Technology for Development, 10(3), 151-169.

Barro, R. J. (1991). Economic growth in a cross-section of countries. Quarterly Journal of Economics, $106,407-443$.

Barro, R. J. (1997). Determinants of economic growth. Cambridge, MA: The MIT Press.

Cronin, F. J., Colleran, E. K., Parker, E. B., \& Dollery, B. (1993). Telecommunications infrastructure investment and economic development. Telecommunications Policy, 17(6), 415-430.

De Silva, H., \& Zainudeen, A. (2007, March). Teleuse on a shoestring: Poverty reduction through telecom access at the bottom of the pyramid. Retrieved August 9, 2007, from www.lirneasia.net

Dewan, S., \& Kraemer, K. L. (2000). Information technology and productivity: Preliminary evidence from country-level data. Management Science, 46, 548-562.

Easterlin, R. (1996). Growth triumphant: The twenty-first century in historical perspective. Ann Arbor: The University of Michigan Press.

Easterly, W., King, R., Levine, R., \& Rebelo, S. (1994). Policy, technology adoption and growth (NBER Working Paper No. 4681). Cambridge, MA: National Bureau of Economic Research.

Economist. (2007, May 10). To do with the price of fish. Retrieved October 16, 2007, from $\mathrm{http} / / / \mathrm{www}$. economist.com/finance/displaystory.cfm?story_id=9149142

Fife, E., \& Hosman, L. (2007). Public private partnerships and the prospects for sustainable ICT projects in the developing world. Journal of Business Systems Governance and Ethics, 2(3), $53-66$.

Hammond, A. (2007). Vice president for innovation, World Resources Institute. Interviews with the authors, June 6 \& November 8. http://www.wri.org

Hosman, L., \& Fife, E. (2008). Improving the prospects for sustainable ICT projects in the developing world. International Journal of Media and Cultural Politics, 4(1), 51-70.

Jensen, R. (2007). The digital provide: Information (technology), market performance, and welfare in the South Indian fisheries sector. Quarterly Journal of Economics, 122(3), 879-924.

Kara, J., \& Quarless, D. (2002). Guiding principles for partnerships for sustainable development ('type 2 outcomes') to be elaborated by interested parties in the context of the World Summit on Sustainable Development (WSSD). Johannesburg Summit, June 7. Retrieved September 9, 2007, from http://www.isd.ca/wssd/download\%20files/annex_partnership.pdf

Kimaro, H.C., \& Sahay, S. (2007). An institutional perspective on the process of decentralization of health information systems: A case study from Tanzania. Information Technology for Development, 13(4), 363-390.

Labelle, R. (2005). ICT policy formulation and e-strategy development: A comprehensive guidebook. UNDP Asia-Pacific Development Programme. New Delhi: Elsevier.

Levine, R., Loayza, N., \& Beck T. (2000). Financial intermediation and growth: Causality and causes. Journal of Monetary Economics, 46, 31-77.

London, T., \& Hart, S. L. (2004). Reinventing strategies for emerging markets: beyond the transnational model. Journal of International Business Studies, 35, 350-370.

McNamara, K. S. (2003). Information and communication technologies, poverty and development: Learning from experience, Washington, DC: The World Bank.

Mutula, S. M., \& Van Brakel, P. (2007). ICT skills readiness for the emerging global digital economy among small businesses in developing countries: Case study of Botswana. Library Hi Tech, 25(2), 231-245.

Norton, S. (1992). Transaction costs, telecommunications, and the microeconomics of macroeconomic growth. Economic Development and Cultural Change, 41(1), 175-96.

Papaioannou, S., \& Dimelis, S. (2007). Information technology as a factor of economic development: Evidence from developed and developing countries. Economic Innovation and New Technology, 16(3), 179-194.

Pohjola, M. (2001). Information technology and economic growth: A cross country analysis. In M. Pohjola (Ed.), Information technology and economic development. Oxford: Oxford University Press.

Quang Ngai Rural Development Programme. (2007). RUDEP Progress Report. Retrieved June 9, 2008, from: www.rudep.org 
Roller, L., \& Waverman, L. (2001). Telecommunications infrastructure and economic development: A simultaneous approach. American Economic Review, 91(4), 909-923.

Sachs, J. (2005a). The end of poverty: Economic possibilities for our time. New York: Penguin Books.

Sachs, J. (2005b). Information and communication technologies for development. In B. Bracey \& T. Culver (Eds.), Harnessing the potential of ICT for education: A multistakeholder approach. New York: United Nations ICT Task Force.

Seo, H. J., \& Lee, Y. S. (2006). Contribution of information and communication technology to total factor productivity and externalities effects. Information Technology for Development, 12(2), 159-173.

Silva, L. (2007). Institutionalization does not occur by decree: Institutional obstacles in implanting a land administration system in a developing country. Information Technology for Development, 13(1), 27-48.

Walsham, G., \& Sahay, S. (2005). Research on information systems in developing countries: Current landscape and future prospects. Information Technology for Development, 12(1), 7-24.

Waverman, L. Meschi, M., \& Fuss, M. (2005). The impact of telecoms on economic growth in developing countries. Paper presented at 2005 TPRC conference. Retrieved November 6, 2007, from: http://web.si.umich.edu/tprc/papers/2005/450/L\%20Waverman-\%20Telecoms\%20Growth\% 20in\%20Dev.\%20Countries.pdf

World Bank. (2004). World development indicators. Washington, DC: The World Bank.

World Bank. (2007). World development indicators. Washington, DC: The World Bank.

Laura Hosman is currently a Ciriacy-Wantrup Postdoctoral Fellow in Natural Resource Economics and Political Economy at the University of California, Berkeley. Her work focuses on the role for information and communications technology (ICT) in developing countries, particularly in terms of its potential effects on socio-cultural factors, human development, and economic growth.

Elizabeth Fife is Principal Researcher at the Institute for Communication Technology Management of the Marshall School of Business at the University of Southern California (USC). Dr. Fife has researched topics such as ICT use in the developing world, IT adoption by small and medium-sized businesses as well as models for technology adoption and diffusion. Current work includes crosscultural analysis of mobile users' behavior. She holds a Ph.D. in International Relations from USC. She also teaches Technical Communications in the Engineering Department at the University.

Laura Elizabeth Armey is a doctoral candidate in Political Economy and Public Policy at the University of Southern California. She teaches micro- and macro-economics at California State University, Channel Islands. She also teaches writing, and is a program manager, at the Writing Program at USC. Her work focuses on the mle of natural resources in conflict. 